\title{
UK medical tourists in Thailand: they are not who you think they are
}

Thinakorn Noree ${ }^{1,2}$, Johanna Hanefeld ${ }^{1,3^{*}}$ and Richard Smith ${ }^{1,4}$

\begin{abstract}
Background: Travel for medical treatment is an aspect of globalization and health that is comparatively less understood. Little is known about volume, characteristic and motivation of medical tourists, limiting understanding of effects on health systems and patients. Thailand is amongst a handful of countries that have positioned themselves as medical tourism destination. This paper examines in unprecedented detail volume and characteristics of medical tourists who travel from the UK to Thailand for treatment.

Methods: As part of a wider medical tourism study, authors gained access to over 4000 patient records from the five largest private hospitals in Thailand. These included information on country of origin, gender, age, arrival month, hospitalization, diagnosis, procedures, length of stay, medical expenditure and type of payment. Patient records were analysed to understand who travels and findings were triangulated with data from the UK International Passenger Survey (IPS).

Results: 104,830 medical tourists visited these hospitals in Thailand in 2010. While patients originate all over the world, UK medical tourists represent the largest group amongst Europeans. The majority UK medical tourists (60\%) have comparatively small, elective procedures, costing less than USD 500. A significant minority of patients travel for more serious orthopedic and cardiothoracic procedures. Data of individual patient records from Thailand shows a higher number of UK patients traveled to Thailand than indicated by the IPS.

Conclusions: Thailand is attracting a large number of medical tourists including larger numbers of UK patients than previously estimated. However, as many patients travel for comparatively minor procedures treatment may not be their primary motivation for travel. The small but significant proportion of older UK residents traveling for complex procedures may point to challenges within the NHS.
\end{abstract}

\section{Introduction}

Over the past decade there has been an increase in people traveling to access medical treatment abroad, including a greater number of UK residents who travel for treatment. This type of travel - where patients travel to another country with the expressed purpose of accessing medical treatment - is commonly referred to as medical tourism [1]. The rise of medical tourism has been as a result of changes associated with globalization, which have seen the emergence of a global infrastructure, including cheaper

\footnotetext{
* Correspondence: Johanna.Hanefeld@lshtm.ac.uk

'Department of Global Health and Development, Faculty of Public Health and Policy London School of Hygiene and Tropical Medicine, Tavistock Place 15-17, London WC1H 9SH, UK

${ }^{3}$ Health Systems Economics, Department of Global Health and Development, Faculty of Public Health and Policy, London School of Hygiene and Tropical Medicine, London, UK

Full list of author information is available at the end of the article
}

flights and greater communication through the internet, which allows providers from one country to market themselves to consumers in another, and greater requirements for out-of-pocket expenditures for healthcare in many countries [2]. Some countries, including Thailand, have marketed themselves as medical tourism destinations, aiming to attract revenue. Thailand adopted a "Thailand: Centre of Excellent Health Care of Asia" policy in 2003, renewed in 2012, and is now one of the most popular destinations for medical tourists. Together with Singapore and India the country now accounts for an estimated $90 \%$ of medical tourism in Southeast Asia [3].

However, despite incidental evidence of individual cases [4] and a growing literature on the topic, empirical information about patients (who they are, their expenditure and the types of treatment they seek abroad for instance) is limited $[1,5,6]$. A number of studies have focused on the

\section{Biomed Central}


medical tourism industry and examined specific aspects of this, including communication and marketing $[2,7,8]$ and practices of different kinds of providers of services $[9,10]$. Yet, information about the effects of such travel on individuals and recipient health systems is still limited [5,11-13]. In the small number of cases where data of the macro level impact of medical tourism on health systems or a countries' economy exists (mainly for Tunisia, countries in the Middle East, Thailand and the UK [3,14-16]), it is not linked to individual patient records. This limits more detailed analysis on the typed of procedures for which patients travel, their country of origin and health and tourism expenditure. Literature focused on the experience of medical tourists on the other hand often focuses on a small number of individual case studies, exploring specific push and pull factors or the patients' experience [17-20], rarely linking individual experiences to systems' effects. This paper addresses this gap. It presents the first analysis of a large dataset of medical tourists in five Thai private hospitals, analyzing in depth the travel for medical treatment from one country - the UK - to comprehensively understand medical travel between two countries. It builds on prior work conducted which examined the systems level impact of medical tourism on the Thai health system $[3,21]$ and it extends this through the analysis of patients procedures. Analysis presented focuses solely on patients from the UK as these emerged as the largest group of Western patients in Thailand, and the authors had conducted prior research on outbound UK medical tourism. This paper provides insights into the largest cohort of UK medical tourists to date. Data is analysed with reference to UK patients' characteristics, procedures and medical expenditure. Insights into patients' characteristics and motivations are discussed as are implications for the UK. A brief comparison with data from the UK International Passenger Survey, conducted by the Office of National Statistics, is included in the discussion.

\section{Methods}

This paper presents the first analysis of a study extensively examining hospital data of medical tourists in Thailand, focused on patients from the UK. It relies on patient records from the five private hospitals in Thailand in 2010. Hospitals were purposely selected, with researchers choosing the five hospitals which catered for the largest number of international patients according to a survey of 55 hospitals conducted by the Thai Ministry of Commerce in 2007. These five hospitals combined accounted for $63 \%$ of all international patients visiting Thailand, while other hospitals surveyed had a market share of less than 1\% each. Three are located in Bangkok and two in high density tourist destinations outside of Bangkok. All hospitals in this study provide highly-specialized tertiary care and different packages of services. Ethical approval for the study was sought and received by the London School of Hygiene Tropical and Medicine and each hospital as well. Confidentiality, record anonymization and data storage were approved by the hospital ethics committee in each of the hospitals studied.

A cross-sectional survey of all medical tourists obtaining medical services in five hospitals was undertaken by analyzing patient records from hospital electronic databases. Expatriates were already excluded in hospital database which identifies them by permanent postal address in Thailand, duration of stay more than six months and whether they work in Thailand. Clinicians in the five hospitals surveyed reported that international tourists who fall ill while on holiday (as opposed to medical tourists traveling with intent to seek treatment) visit the hospital with acute symptoms related to travelling activities, such as common cold, acute diarrhea, sun burn or accident. Based on this information, tourists who had fallen ill while on holiday were excluded using the patients' diagnosis based on ICD-10 classification. Ten variables in terms of demography and service profiles from each patient record, including (1) country of origin, (2) gender, (3) age (4) arrival month, (5) hospitalization, (6) diagnosis, (7) procedures, (8) length of stay, (9) medical expenditure and (10) type of payment were analyzed. Findings from the analysis of data on UK medical tourists from the five hospitals were then triangulated with analysis of the UK International Passenger Survey (IPS) to better understand overall volume of patients traveling and data.

Analysis of the IPS data 2000-2010 was conducted as part of a larger research project on UK medical tourism, findings of which are published separately [16]. The IPS is conducted by the UK Office of National Statistics (ONS), which randomly surveys a representative sample of passengers entering and exiting the UK. These results are then used by the ONS to estimate tourism to and from the UK. It asks a range of questions of travelers including about demographic factors, origin and destination of passengers and their primary purpose of travel [16]. Passengers leaving the UK to travel to Thailand and stating medical treatment as their primary purpose of travel are thus reflected in the IPS figures. Thus the IPS represents a very different type of data (an estimate) compared to the number of actual patient records surveyed and analysed from Thai hospitals. Authors included the IPS, despite this difference as having access and conducted analysis of datasets from an 'originating' country - the UK, and a recipient country - Thailandis unique in the literature and, crucially, allowed for triangulation of the UK IPS. 


\section{Results}

Key findings from medical records of UK medical tourist in $\mathbf{2 0 1 0}$

\section{Medical tourism to Thailand in 2010}

A total of 104,830 medical tourists visited the five private hospitals surveyed in 2010. Most of these visited the hospital more than once - these patients accounted for 324,926 separate visits. Medical revenue generated for the hospitals from these patients was 180 million USD.

These patients originated from all over the world, with the majority - approximately 40\% - from the Middle East. These are followed by patients from Southeast Asia, Europe, South Asia and from North America respectively. The high number of patients originating in the Middle East is likely to be because the two largest hospitals included in this study are located in a predominately Middle Eastern neighbourhood in central Bangkok, providing close informal links and advertising. Most patients come from the UAE, followed by Bangladesh and the USA. The largest number of patients from Europe are from the UK (Table 1).

\section{UK Medical tourists to Thailand}

Demographic profiles In 2010, almost 4,000 UK patients travelled to Thailand to access medical treatment (Table 1), accounting for $3.75 \%$ of medical tourists and approximately 11,000 visits.

Of UK patients $69 \%$ are male and $31 \%$ are female (Table 2) and the largest group (26\%) are between 45-54 years old, with the average age of a patient being 46.52 years. Male patients are older than female ones, being 48.2 and
42.7 years old respectively. It is noteworthy that almost $11 \%$ of patients are aged over 65 .

Patients from Europe, including the UK, tend to visit Thailand between November and March, pointing to the seasonal nature of medical tourism (ie during the cold months of Europe). In addition, during the 2010 political conflict in Thailand [22], a clear drop in patients visiting for treatment was evident in the hospital's patient data, but this recovered quickly once the unrest was resolved.

Treatment profiles The vast majority of UK patients 93\% - accessed treatment as out-patients, with only seven percent requiring hospital admission. For those admitted, data shows $32 \%$ stay in hospital for only a day, with $17.81 \%$ and $14.89 \%$ being admitted for two and three days respectively; i.e. $65 \%$ of those requiring in patient care do so for less than three days (Table 3 ). However, around 10\% of those required hospitalized for more than two weeks, with $5 \%$ of patients staying more than 30 days. $60 \%$ of patients were men and $40 \%$ women.

\section{Types of procedure}

467 types of procedures were performed on UK patients across the five hospitals during the timespan surveyed, for the purposes of this analysis these were grouped into subcategories of top ten procedures. The distribution of procedures is listed in Table 4. Operations on integument system (mostly breast and facelifts) are the most common procedures, accounting for $25 \%$ of total procedures in UK patients, followed by operations on musculo-skeleton, eyes and digestive system respectively (Table 4). Male patients have the major share of all procedures except for cosmetic

Table 1 Top-fifteen countries providing medical tourists to Thailand in $\mathbf{2 0 1 0}$

\begin{tabular}{|c|c|c|c|c|c|c|}
\hline & & \multicolumn{2}{|c|}{ Patients } & \multicolumn{2}{|c|}{ Visits } & \multirow{2}{*}{$\begin{array}{l}\text { Average } \\
\text { visits/year }\end{array}$} \\
\hline & & Frequency & Percent & Frequency & Percent & \\
\hline 1 & U.A.E. & 21,568 & 20.57 & 63,457 & 19.53 & 2.94 \\
\hline 2 & Bangladesh & 8,443 & 8.05 & 26,338 & 8.11 & 3.12 \\
\hline 3 & USA & 7,855 & 7.49 & 24,262 & 7.47 & 3.09 \\
\hline 4 & Myanmar & 7,568 & 7.22 & 32,940 & 10.14 & 4.35 \\
\hline 5 & Oman & 7,096 & 6.77 & 21,699 & 6.68 & 3.06 \\
\hline 6 & Qatar & 5,212 & 4.97 & 17,784 & 5.47 & 3.41 \\
\hline 7 & United Kingdom & 3,935 & 3.75 & 10,779 & 3.32 & 2.74 \\
\hline 8 & Other African countries & 3,857 & 3.68 & 17,491 & 5.38 & 4.53 \\
\hline 9 & Cambodia & 3,837 & 3.66 & 10,919 & 3.36 & 2.85 \\
\hline 10 & Australia & 3,360 & 3.21 & 10,136 & 3.12 & 3.02 \\
\hline 11 & Kuwait & 3,159 & 3.01 & 11,330 & 3.49 & 3.59 \\
\hline 12 & Japan & 1,995 & 1.90 & 4,681 & 1.44 & 2.35 \\
\hline 13 & France & 1,742 & 1.66 & 4,275 & 1.32 & 2.45 \\
\hline 14 & Germany & 1,545 & 1.47 & 3,780 & 1.16 & 2.45 \\
\hline 15 & Canada & 1,474 & 1.41 & 4,115 & 1.27 & 2.79 \\
\hline
\end{tabular}


Table 2 Age distribution of UK patients

\begin{tabular}{llcccc}
\hline & & \multicolumn{2}{c}{ Gender } & Total & $\%$ \\
\cline { 3 - 4 } Agle & Female & & \\
\hline Age group & Less than 25 years & 149 & 172 & 321 & 8.16 \\
& 25-34 years & 299 & 199 & 498 & 12.67 \\
& 35-44 years & 561 & 258 & 819 & 20.83 \\
45-54 years & 724 & 291 & 1,015 & 25.81 \\
& 55-64 years & 630 & 200 & 830 & 21.11 \\
& More than 65 years & 338 & 111 & 449 & 11.42 \\
& Total & $\mathbf{2 , 7 0 1}$ & $\mathbf{1 , 2 3 1}$ & $\mathbf{3 , 9 3 2}$ & $\mathbf{1 0 0 . 0 0}$ \\
& & & & \\
& & & & &
\end{tabular}

related procedures (integument, eyes and nose) and those on female genital organs (Figure 1). Women make up the vast majority of patients for cosmetic surgery. There is also a slight age difference between patients; those undertaking cosmetic procedures are on average younger than orthopedic patients (Figures 2 and 3 ).

\section{Medical expenditure}

The largest group of out-patients (which constitute 93\% of all UK medical tourists) - around 40\% - pay less than 100 USD per visit (Table 5), with 28\% paying between 100 and 500 USD per visit, i.e. almost $60 \%$ of patient pay less than 500USD. While $22 \%$ of patients pay between 1000 and 5000 USD, most revenue from outpatients is less much less, with average out-patient expenditure at 467 USD (median 160 USD). This contrasts with the small number of in-patients, whose costs are much higher (again as evident in Table 5), with an average in-patient expenditure of 13,955 USD per admission (median 7,522 USD).

\section{Discussion}

Data shows around 4000 UK medical tourists visited the five largest private hospitals in Thailand in 2010. Two thirds of these are men and one third women. This differs from evidence available through the Office of National Statistic's International Passenger Survey (IPS). According to IPS data in 2010, only 500 UK residents travelled to Thailand for medical treatment. Data from the IPS also

Table 3 Length of stay

\begin{tabular}{lcc}
\hline & Number of admissions & $\%$ \\
\hline 1 day & 219 & 31.97 \\
2 days & 122 & 17.81 \\
3 days & 102 & 14.89 \\
$4-7$ days & 121 & 17.66 \\
8-14 days & 53 & 7.74 \\
$15-30$ days & 35 & 5.11 \\
31-60 days & 33 & 4.82 \\
Total & $\mathbf{6 8 5}$ & $\mathbf{1 0 0 . 0 0}$ \\
\hline
\end{tabular}

Table 4 Distribution of procedures in UK medical tourists by ICD-9 classification

\begin{tabular}{|c|c|c|c|}
\hline & Type of procedure & Total & $\%$ Total \\
\hline 1 & $\begin{array}{l}\text { Operation on the integumentary } \\
\text { (mostly breast and facelift) system (85-86) }\end{array}$ & 121 & 25.91 \\
\hline 2 & $\begin{array}{l}\text { Operation on the musculoskeleton } \\
\text { system (76-84) }\end{array}$ & 65 & 13.92 \\
\hline 3 & Operation on the eyes (08-16) & 55 & 11.78 \\
\hline 4 & Operation on the digestive system $(42-54)$ & 51 & 10.92 \\
\hline 5 & $\begin{array}{l}\text { Miscellaneous diagnostic and } \\
\text { therapeutic procedures (87-99) }\end{array}$ & 41 & 8.78 \\
\hline 6 & Operation on the cardiovascular system (35-39) & 21 & 4.50 \\
\hline 7 & $\begin{array}{l}\text { Procedures and interventions, not elsewhere } \\
\text { classified (00) (Mostly coronary artery stent) }\end{array}$ & 19 & 4.07 \\
\hline 8 & $\begin{array}{l}\text { Operation on the nose, mouth and } \\
\text { pharynx (21-29) }\end{array}$ & 18 & 3.85 \\
\hline 9 & Operation on the female genital organ (65-71) & 16 & 3.43 \\
\hline 10 & Operations on the nervous system (01-05) & 13 & 2.78 \\
\hline 11 & Operation on the urinary system (55-59) & 13 & 2.78 \\
\hline 12 & Operation on the male genital organ (60-64) & 12 & 2.57 \\
\hline 13 & Operations on the endocrine system (06-07) & 9 & 1.93 \\
\hline 14 & Obstetric procedures (72-75) & 4 & 0.86 \\
\hline 15 & $\begin{array}{l}\text { Other miscellaneous diagnostic and therapeutic } \\
\text { procedures [17] }\end{array}$ & 3 & 0.64 \\
\hline 16 & Operation on the respiratory system (30-34) & 3 & 0.64 \\
\hline 17 & $\begin{array}{l}\text { Operation on the hemic and lymphatic } \\
\text { system (40-41) }\end{array}$ & 2 & 0.43 \\
\hline 18 & Operation on the ears [18-20] & 1 & 0.21 \\
\hline Total & & 467 & 100.00 \\
\hline
\end{tabular}

indicates that the majority of medical tourists from the UK are women and that over the past decade the largest percentage of travelers have been in the age group of 2534 year olds. Comparison of hospital data with the International Passenger Survey highlights different specificities of tourists traveling to Thailand (predominately male and older than UK medical tourists traveling to other destinations). The difference between the IPS data and the findings of this survey of UK medical tourists in Thailand are likely due to the differences in methodology used. Yet, it highlights the limits of the information on UK medical tourists available through the IPS.

Our analysis shows that the majority of patients from the UK travel for comparatively low-cost procedures. As $60 \%$ of patients' treatment costs are below USD 500, these were likely significantly lower than the cost of travel to Thailand. This figure points to a significant proportion of people who may simply 'add' surgery onto a holiday, or at a minimum have a substantial leisure tourism element as part of their medical travel. It is underlined by the seasonal nature of medical tourism with most patients traveling 


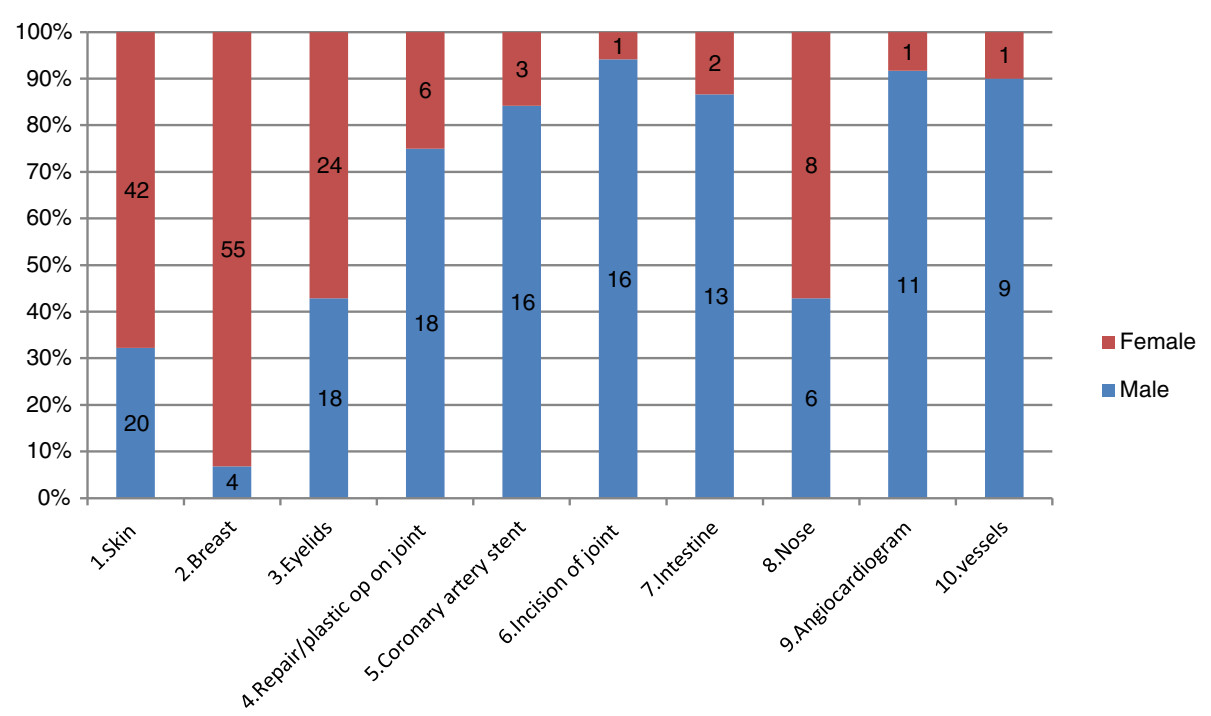

Figure 1 Top 10 procedures among UK medical tourists by gender.

between November and March, when weather may be a significant factor in patients' decision to travel to Thailand. The low cost of cosmetic procedures is likely to be a significant motivation. The comparatively smaller amount of resources spent on medical treatment differs from survey results conducted in Europe, where average treatment costs were much higher [23].

Moreover, findings highlight that UK tourists return to Thailand for treatment, and that given the higher number of visits than patients some UK medical tourists may opt for a series of smaller procedures rather than undertake a large procedure.

Despite the majority of patients traveling for out-patient, elective procedures, a number of patients received more complex treatment, such as orthopedic and cardiothoracic procedures, with a small number remaining in hospital for over ten or even 30 days. A comparatively greater number of patients receiving more complex treatment are older. Given the nature of the procedures it is likely that patients would have been entitled to these under the NHS. Further

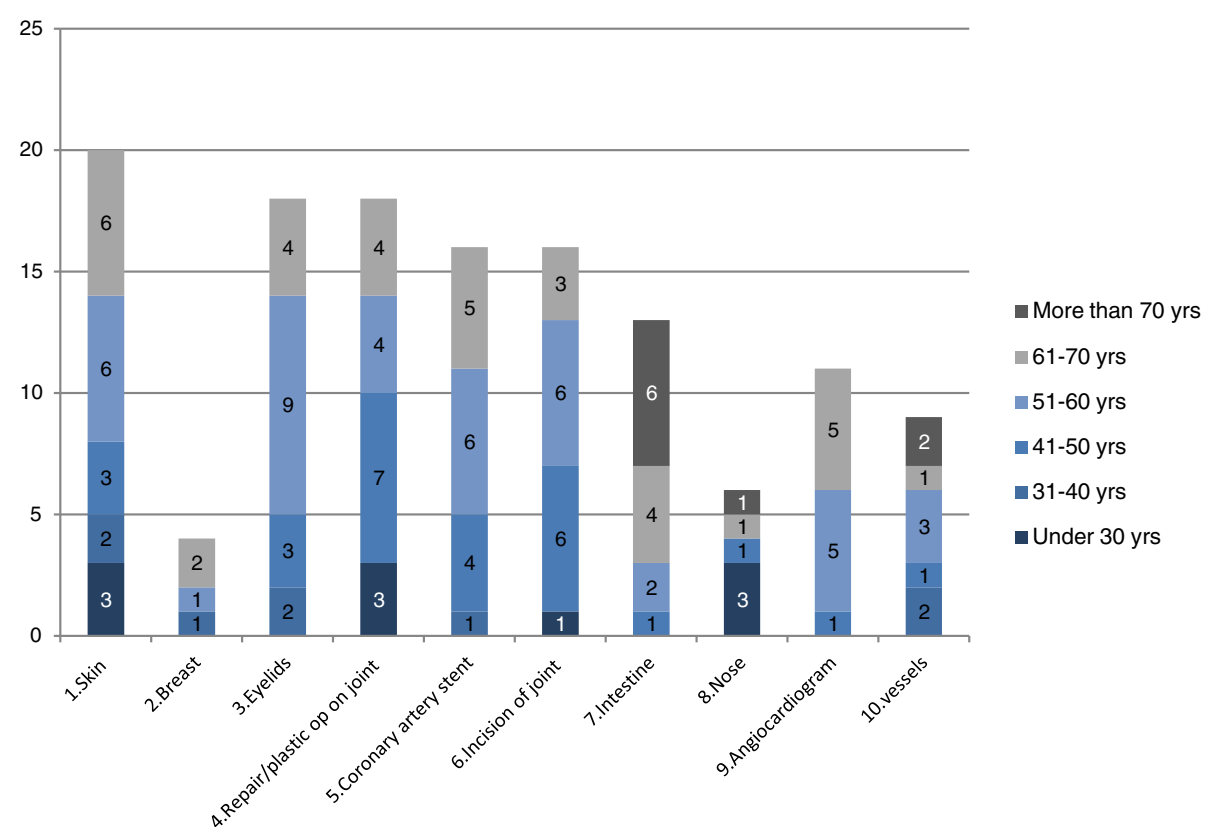

Figure 2 Top 10 procedures among male UK medical tourist by age group. 


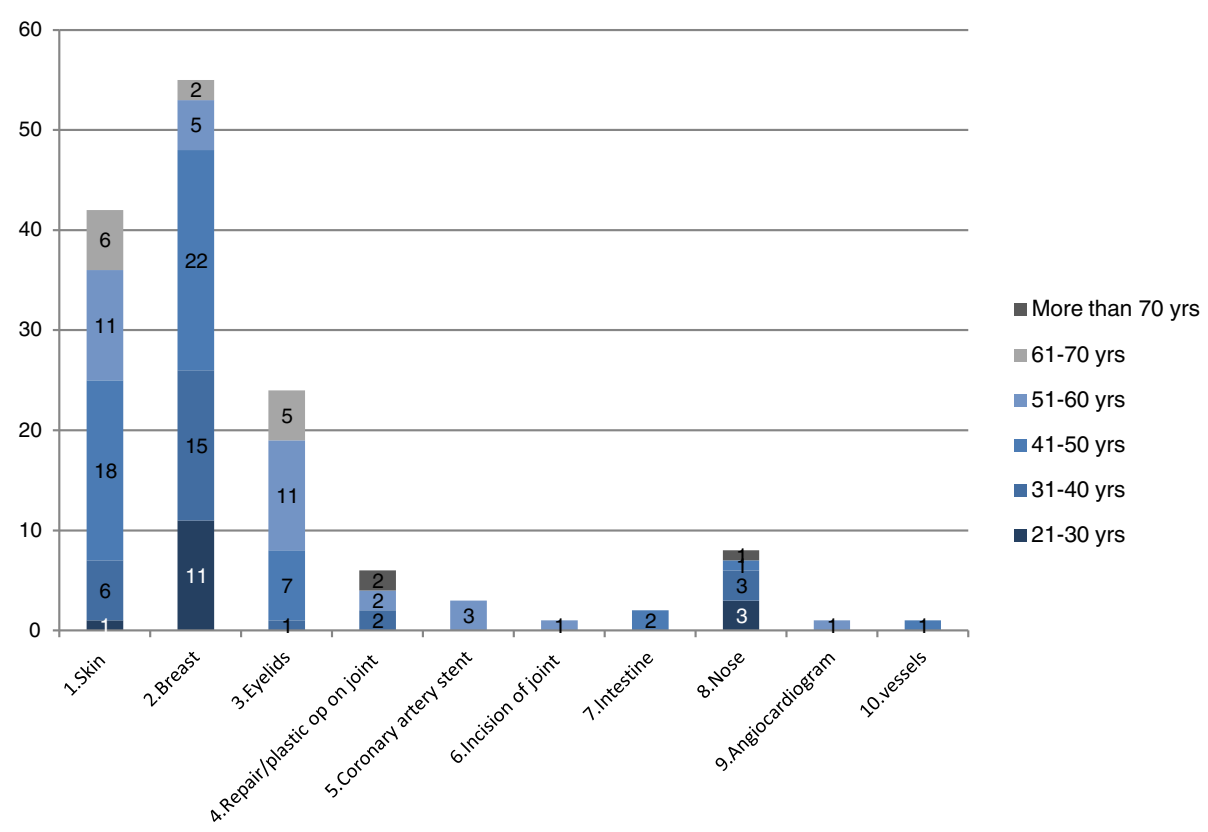

Figure 3 Top 10 procedures among female UK medical tourist by age group.

research is needed to understand why these patients may choose to travel.

The idea of a simple 'add on' of a small type of treatment is very different to the kind 'intent for treatment' which is associated with medical tourism and its definitions in the literature [1]. The mix of patients those with more serious conditions traveling as well as those seeking only smaller types of treatment, suggests that medical tourists are a heterogeneous group.

\section{Conclusion}

Almost 4000 UK medical tourists visit Thailand for treatment annually. While the most popular procedures are elective, UK patients travel for procedures, such as orthopedics and cardiothoracic, for which they would be eligible under the NHS.
Policymakers in the UK need to consider carefully how to reach different groups of patients when thinking about safeguards for UK patients who travel, including in terms of adequate information on quality and risk. Information provided by our analysis also highlights who should receive priority in terms of being targeted with information. While clearly a large number of patients simply travel for small procedures and in particular cosmetic surgery, a small number of older patients travel for more complex orthopedic surgery. This evidence provides an entry point for providing information on safety and risk to UK citizens. The number of patients who travel to Thailand for cosmetic procedures underline the importance of including a focus on medical tourists in the current considerations of regulation of advertising for cosmetic surgery in the UK.

Table 5 Medical expenditure of UK medical tourists

\begin{tabular}{|c|c|c|c|c|c|c|}
\hline & \multicolumn{2}{|c|}{ Out-patient } & \multicolumn{2}{|l|}{ In-patient } & \multirow[t]{2}{*}{ Total } & \multirow[t]{2}{*}{$\%$} \\
\hline & Number of visits & $\%$ & Number of admission & $\%$ & & \\
\hline Less than 100 USD & 4,034 & 40.15 & 0 & 0.00 & 4,034 & 37.45 \\
\hline $100-500$ USD & 2,854 & 28.41 & 5 & 0.69 & 2,859 & 26.54 \\
\hline 500-1,000 USD & 893 & 8.89 & 26 & 3.58 & 919 & 8.53 \\
\hline $1,000-5,000$ USD & 2,253 & 22.42 & 180 & 24.79 & 2,433 & 22.58 \\
\hline $5,000-10,000$ USD & 12 & 0.12 & 245 & 33.75 & 257 & 2.39 \\
\hline $10,000-50,000$ USD & 1 & 0.01 & 221 & 30.44 & 222 & 2.06 \\
\hline $50,000-100,000$ USD & 0 & 0.00 & 39 & 5.37 & 39 & 0.36 \\
\hline More than 100,000 USD & 0 & 0.00 & 10 & 1.38 & 10 & 0.09 \\
\hline Total & 10,047 & 100.00 & 726 & 100.00 & 10,773 & 100.00 \\
\hline
\end{tabular}


This empirical study adds to the small but growing body of evidence which suggests that medical tourists and medical tourism may be a less unified phenomenon than previously presented in the literature [7].

Finally, a large -scale data set from providers in one medical tourism destination - Thailand - indicates the limitations of current evidence on volume of UK medical tourism available through the IPS. Better data is needed to fully understand UK medical travel and its likely impact on patients and the NHS. Our findings suggest that current data may underestimate the number of UK passengers who travel to access treatment abroad.

\section{Competing interest}

The authors declare that they have no competing of interest.

\section{Authors' contributions}

TN designed and carried out the data collection and analysis for the study with input from $\mathrm{JH}$ and RS. $\mathrm{JH}$ and TN provided an initial draft based on the data analysed. All authors reviewed and revised the draft.

\section{Acknowledgements}

TN conceived of the overall study and collected data with input and supervision by RS. TN conducted the analysis with input from JH and RS. JH conducted the analysis of the IPS. All authors met to discuss the findings. TN and $\mathrm{JH}$ drafted the initial paper which was revised by RS. This study is part of TN's PhD, RS is lead supervisor, JH co-supervisor.

\section{Author details}

${ }^{1}$ Department of Global Health and Development, Faculty of Public Health and Policy London School of Hygiene and Tropical Medicine, Tavistock Place 15-17, London WC1H 9SH, UK. International Health Policy Program, The Ministry of Public Health, Bangkok, Thailand. ${ }^{3}$ Health Systems Economics, Department of Global Health and Development, Faculty of Public Health and Policy, London School of Hygiene and Tropical Medicine, London, UK. ${ }^{4}$ Health System Economics \& Dean of Faculty of Public Health \& Policy, London School of Hygiene \& Tropical Medicine, London, UK.

Received: 15 July 2013 Accepted: 2 April 2014

Published: 6 May 2014

\section{References}

1. Connell J: Contemporary medical tourism: Conceptualisation, culture and commodification. Tour Manage 2013, 34(0):1-13.

2. Lunt N, Hardey M, Mannion R: Nip, tuck and click: medical tourism and the emergence of web-based health information. Open Med Inform J 2010, 4:1-11. PubMed PMID: 20517465. Pubmed Central PMCID: 2874214. Epub 2010/06/03. eng.

3. NaRanong A, NaRanong $V$ : The effects of medical tourism: Thailand's experience. Bull World Health Organ 2011, 89(5):336-344. PubMed PMID: 21556301. English.

4. Hanna SA, Saksena J, Legge S, Ware HE: Sending NHS patients for operations abroad: is the holiday over? Ann R Coll Surg Engl 2009, 91(2):128-130. PubMed PMID: ISI:000264420700011. English.

5. Crooks VA, Kingsbury P, Snyder J, Johnston R: What is known about the patient's experience of medical tourism? A scoping review. BMC Health Serv Res 2010, 10:266. PubMed PMID: 20825667. English.

6. Hudson N, Culley L, Blyth E, Norton W, Rapport F, Pacey A: Cross-border reproductive care: a review of the literature. Reprod Biomed Online 2011, 22(7):673-685. PubMed PMID: 21498121. English.

7. Lunt N, Horsfall D, Exworthy M, Smith R, Hanefeld J: Market size, market share and market strategy: three myths of medical tourism. Policy Politics 2013, http://dx.doi.org/10.1332/030557312X655918.

8. Horsfall DG, Lunt N, King H, Hanefeld J, Smith RD: The impact of the internet on medical tourism. In Medical Tourism and Transnational Health Care. Edited by Botterill D, Pennings G. London: Palgrave Macmillan; 2013.

9. Snyder J, Crooks VA, Adams K, Kingsbury P, Johnston R: The 'patient's physician one-step removed': the evolving roles of medical tourism facilitators. J Med Ethics 2011, 37(9):530-534. PubMed PMID: |SI:000294044300004. English.

10. Johnston R, Crooks VA, Adams K, Snyder J, Kingsbury P: An industry perspective on Canadian patients' involvement in Medical Tourism: implications for public health. BMC Public Health 2011, 31:11. PubMed PMID: ISI:000291792900001. English.

11. Johnston R, Crooks VA, Snyder J, Kingsbury P: What is known about the effects of medical tourism in destination and departure countries? A scoping review. Int J Equity Health 2010, 9(24): doi:10.1186/1475-9276-9-24.

12. Hanefeld J, Smith DR, Lunt N, Horsfall D: What do we know about medical tourism a review of the literature with discussion of its implications for the UK NHS as an example of a public health care system. J Medical Travel 2014, forthcoming.

13. Smith RD, Chanda R, Tangcharoensathien V: Trade in health-related services. Lancet 2009, 373(9663):593-601. PubMed PMID: 19167053. Epub 2009/01/27. eng.

14. Siddiqi S, Shennawy A, Mirza Z, Drager N, Sabri B: Assessing trade in health services in countries of the Eastern Mediterranean from a public health perspective. Int J of Health Plann Manag 2010, 25(3):50-231. PubMed PMID: 19676048. English.

15. Lautier M: Export of health services from developing countries: The case of Tunisia. Soc Sci Med 2008, 67(1):10-101. PubMed PMID: |SI:000257346300014. English.

16. Hanefeld J, Horsfall D, Lunt N, Smith R: Medical Tourism: A Cost or Benefit to the NHS? PLos One 2013, 8(10):e70406.

17. Solomon $\mathrm{H}$ : Affective journeys: the emotional structuring of medical tourism in India. Anthropol Med 2011, 18(1):18-105. PubMed PMID: 21563006. English.

18. Lee JY, Kearns RA, Friesen W: Seeking affective health care: Korean immigrants' use of homeland medical services. Health Place 2010, 16(1):15-108. PubMed PMID: ISI:000272790200014. English.

19. Snyder J, Crooks VA: Medical Tourism and Bariatric Surgery: More Moral Challenges. Am J Bioeth 2010, 10(12):28-30.

20. Culley L, Hudson N, Rapport F, Blyth E, Norton W, Pacey AA: Crossing borders for fertility treatment: motivations, destinations and outcomes of UK fertility travellers. Hum Reprod 2011, 26(9):2373-81. PubMed PMID: |SI:000294073400015. English.

21. Pachanee $\mathrm{C}-\mathrm{a}$, Wibulpolprasert S: Incoherent policies on universal coverage of health insurance and promotion of international trade in health services in Thailand. Health Policy Plan 2006, 21(4):8-310.

22. The Economist: The battle for Thailand. UK: The Economist Newspaper Limited; 2010

23. Abroad T: The Medical Tourism Survey 2012. Online: Treatment Abroad. Intuition Communication Ltd. : Berkhamsted, Hertfordshire, United Kingdom; 2012

doi:10.1186/1744-8603-10-29

Cite this article as: Noree et al:: UK medical tourists in Thailand: they are not who you think they are. Globalization and Health 2014 10:29.

\section{Submit your next manuscript to BioMed Central and take full advantage of:}

- Convenient online submission

- Thorough peer review

- No space constraints or color figure charges

- Immediate publication on acceptance

- Inclusion in PubMed, CAS, Scopus and Google Scholar

- Research which is freely available for redistribution 